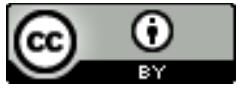

\title{
ANÁLISE DOS PROJETOS DE ENSINO, PESQUISA E EXTENSÃO FIRMADOS PELA UFSC COM SUAS FUNDAÇÕES DE APOIO NO ANO DE 2015
}

\author{
ANALYSIS OF TEACHING, RESEARCH AND EXTENSION PROJECTS SIGNED BY UFSC \\ WITH ITS FOUNDATIONS OF SUPPORT IN THE 2015 YEAR \\ ANÁLISIS DE LOS PROYECTOS DE ENSEÑANZA, INVESTIGACIÓN Y EXTENSIÓN \\ SUSCRITO POR UFSC CON SUS FUNDACIONES DE APOYO EN AÑO 2015
}

\section{Lilian Wrzesinski Simon' \\ Carla Cerdote da Silva Antonio Marcos Machado \\ José Alvicio Ritter Filho \\ Larissa Espíndola Machado Pereira Alexandre Moraes Ramos}

\begin{abstract}
RESUMO: Este artigo tem como objetivo analisar o quantitativo e volume financeiro dos projetos de ensino, pesquisa e extensão, firmados pelas Fundações de Apoio no âmbito dos Centros de Ensino da UFSC, durante o ano de 2015. A pesquisa caracteriza-se como descritiva, bibliográfica e documental, com abordagem qualitativa e quantitativa. A partir do levantamento das informações disponibilizadas pelas quatro Fundações de Apoio da UFSC foram analisados os projetos gerenciados em cada uma delas, seus respectivos valores, suas áreas de atuação - entre ensino, pesquisa e extensão e as distribuições destes pelos Centros de Ensino da instituição. A análise dos dados demonstrou que a UFSC se destaca na área da pesquisa em campos como a tecnologia e inovação e na extensão em áreas como a saúde e a tecnologia. No que tange aos recursos financeiros, observa-se que há concentração de projetos e movimentação de recursos em três Fundações de Apoio de forma homogênea. Esta característica persiste na alocação dos recursos por Centro de Ensino, assim como no montante de recursos destinados a projetos de extensão.
\end{abstract}

PAlAVRAS-ChaVE: Fundações de apoio. Administração universitária. Universidade e sociedade. Governança.

ABSTRACT: This article aims to analyze the amount and financial volume of teaching, research and extension projects, signed by the Supporting Foundations within the scope of the UFSC Teaching Centers, during the 2015 year. The research is characterized as descriptive, bibliographical and documentary, with qualitative and quantitative approach. From the information gathered by the four Foundations of Support of the UFSC, the projects managed in each one of them, their respective values, their areas of action - between teaching, research and extension and the distributions of these by the Institution's Teaching Centers. Data analysis showed that UFSC stands out in the field of research in fields such as technology and innovation and the extension in areas such as health and technology. With regard to financial resources, it is observed that there is concentration of projects and movement of resources in three Supporting Foundations in a homogeneous way. This characteristic persists in the allocation of resources by Education Center, as well as in the amount of resources destined to extension projects.

KEYWORDS: Foundations of support. University administration. University and society. Governance.

RESUMEN: Este artículo tiene como objetivo analizar la cantidad y el volumen financiero de los proyectos de enseñanza, investigación y extensión, firmados por las fundaciones de apoyo en el ámbito de los centros de

Submetido em: 14/03/2017 - Aceito em: 08/06/2017 - Publicado em: 04/07/2017. 
aprendizaje de la UFSC durante el año 2015. La investigación se caracteriza como descriptivo, bibliográfico y documental, información cualitativa y cuantitativa enfoque. A partir de la encuesta de la información proporcionada por cuatro de las Fundaciones de Apoyo la UFSC fueron analizados los proyectos manejados en cada uno de ellos, sus valores, sus campos - entre la enseñanza, la investigación y la extensión y la distribución de estos por los centros de enseñanza la institución. El análisis de los datos mostró que la UFSC se destaca en el área de investigación en campos como la tecnología y la innovación y extensión en áreas como la salud y la tecnología. En lo que respecta a los recursos financieros, se observa que hay una concentración de proyectos y transferencias de fondos en tres fundaciones de apoyo de forma homogénea. Esta característica persiste en la asignación de recursos para el Centro de Aprendizaje, así como la cantidad de recursos para los proyectos de extensión.

PALABRAS CLAVE: Fundaciones de apoyo. Administración de la universidad. Universidad y la sociedad.

Gobernabilidad.

\section{INTRODUÇÃO}

A interação das Instituições Federais de Ensino Superior (IFES) com as Fundações de Apoio (FAs) não é recente e tampouco trata-se de um assunto pouco discutido no âmbito das universidades federais. As FAs são instituições de fins determinados, criadas para o atendimento de finalidades conforme a vontade de seu instituidor. Possuem natureza jurídica de direito privado, sem fins lucrativos, e atuam mediante credenciamento prévio junto ao Ministério da Educação (MEC) e Ministério da Ciência, Tecnologia e Inovação (MCTI), de acordo com a Lei $n^{\circ}$ 8.958/94 (BRASIL, 1994), Decreto $n^{\circ}$ 7.423/10 (BRASIL, 2010) e Portaria Interministerial no 191/12 MEC/MCTI (CONFIES, 2016).

Conforme o Art. 207 da Constituição Federal de 1988 (BRASIL, 1988), as universidades obedecerão ao princípio de indissociabilidade entre ensino, pesquisa e extensão. Diante da intensificação da necessidade de potencializar os investimentos nestas áreas, a partir da década de 90, as universidades públicas federais passaram a buscar fontes adicionais de financiamento junto aos poderes públicos e à iniciativa privada para o desenvolvimento de seus projetos, o que contribuiu para o estreitamento e intensificação das parcerias com as FAs.

As FAs foram criadas com a finalidade de apoiar, administrar e gerenciar a execução de projetos de interesse das Instituições Federais de Ensino Superior (IFES), das instituições de pesquisa e demais Instituições Científicas e Tecnológicas (ICTs), por meio da celebração de convênios e contratos por prazo determinado, nos termos da Lei $n^{\circ}$ 8.958/94 (MEC, 2015; BRASIL, 1994).

A Universidade Federal de Santa Catarina (UFSC) conta hoje com a parceria de 4 FAs que administram e gerenciam recursos por meio de contratos e convênios firmados para o desenvolvimento de projetos em diversas áreas do conhecimento. As FAs da UFSC são: a Fundação José Arthur Boiteux - FUNJAB, Fundação de Ensino e Engenharia de Santa Catarina - FEESC, a Fundação de Amparo à Pesquisa e Extensão Universitária - FAPEU e a 
Fundação de Estudos e Pesquisas Socioeconômicos - FEPESE. Todas elas estão devidamente credenciadas pelo MEC e pelo MCTI, sendo este um dos requisitos necessários para a devida atuação junto à instituição a qual estão vinculadas.

A UFSC é constituída por 11 Centros de Ensino e 5 campi habilitados para desenvolverem projetos em conjunto com as Fundações de Apoio. Com a aprovação das Resoluções Normativas internas RN no 47/CUn/2014, RN no 03/CUn/2009 e RN no 15/CUn/2011, que regulamentam as ações no interior da UFSC para o desenvolvimento das atividades de pesquisa e extensão e pós graduação lato sensu (ensino), consagrou-se a regulação destas ações.

Neste contexto, procura-se analisar o volume de projetos de ensino, pesquisa e extensão, gerenciados pelas FAs no âmbito dos Centros de Ensino da UFSC, durante o ano de 2015 e o valor financeiro correspondente. Partindo deste prisma, pretende-se tecer um panorama dos projetos firmados pelas FAs que predominam na instituição e das áreas às quais estão vinculados.

Para alcançar esse objetivo são consideradas algumas premissas que foram adotadas para nortear o desenvolvimento da pesquisa, tais como: levantar os valores financeiros firmados entre as FAs e a UFSC no ano de 2015; apresentar a distribuição destes recursos entre as áreas de ensino, pesquisa e extensão; demonstrar e analisar a distribuição quantitativa dos projetos firmados entre a UFSC e as FAs e o volume financeiro movimentado por Centro de Ensino. A análise proposta permite também a visualização do total de recursos movimentados pelas FAs e a efetiva participação dos Centros de Ensino nesses projetos, sendo uma fonte de informação acerca do perfil institucional da UFSC no que se refere ao ensino, pesquisa e a extensão.

Para tanto, esse artigo lança mão de alguns procedimentos metodológicos e aspectos teóricos que permitem a contextualização do fenômeno de estudo estabelecendo critérios para a análise dos dados e apresentação de seus resultados.

\section{PROCEDIMENTOS METODOLÓGICOS}

Essa pesquisa de cunho descritivo busca representar as características de um determinado fenômeno, representado aqui pela atuação da UFSC no que se refere aos projetos de ensino, pesquisa e extensão desenvolvidos em parceria com as suas FAs. Quanto à natureza de suas fontes, apresenta-se como bibliográfica e documental, com enfoque direcionado para as FAs, seus relatórios de gestão e demais dados necessários à análise e comparação dos dados acerca de seus projetos (VERGARA, 2013; GIL, 2002).

A abordagem é quali-quanti, sendo que os dados empíricos foram obtidos através da incursão 
nas publicações dos relatórios anuais de gestão disponibilizados pelas FAs e também nas informações dos projetos em suas páginas na internet (MINAYO; SANCHES, 1993; GOLDENBERG, 2004).

A coleta dos dados foi realizada por meio de uma pesquisa documental no site das fundações, a partir de informações públicas (GIL, 2002), Essas informações foram sistematizadas por meio do método estatístico, sem sofrer nenhum tipo de modificação na sua rubrica original (LAKATOS; MARCONI, 2003).

Os dados foram organizados e tabulados em gráficos demonstrativos e analisados qualitativamente, pois entendeu-se que essas métricas combinadas possibilitariam o confronto dos resultados, contribuindo para a sua confiabilidade e respondendo aos pressupostos definidos inicialmente para direcionar essa abordagem (MINAYO; SANCHES, 1993; GOLDENBERG, 2004).

A análise dos projetos firmados no ano de 2015 pela soma da participação de cada uma das quatro FAs que atuam na UFSC e a distribuição destes entre os seus 11 Centros de Ensino e os 5 campi valeu-se do estudo comparativo, de forma que foi possível evidenciar diversas aferições: por tipo de projeto (ensino, pesquisa e extensão), por fundação, por Centro de Ensino e, de acordo com o volume de recursos (VERGARA, 2013). Assim, a partir da classificação dos projetos foi demonstrada em números percentuais a participação de cada fundação, cada área e cada Centro de Ensino, de forma que foi possível a representação de várias perspectivas de análise, de acordo com o objetivo.

\section{A RELAÇÃo ENTRE AS UNIVERSIDADES E AS FUNDAÇõeS DE APOIO}

A fim de subsidiar a análise, apresentam-se alguns conceitos acerca das IFES e das FAs que permitem delinear as relações destas sob a ótica da gestão dos projetos de ensino, pesquisa e extensão. As universidades se diferenciam das demais instituições de ensino, pois estão sujeitas à indissociabilidade entre essas três áreas (BRASIL, 1988).

A organização legislativa brasileira conferiu à União, aos Estados e aos Municípios a implantação de universidades públicas, cabendo a esses a responsabilidade pelo financiamento e custeio das atividades acadêmicas e administrativas (BRASIL, 1996). No entanto, os recursos provenientes pura e exclusivamente dos governos são insuficientes para atenderem a todas as necessidades existentes nas universidades públicas para a execução de uma educação superior pública, democrática e de qualidade (SOBRINHO, 2010).

Assim, além do seu orçamento, a universidade pública recebe a descentralização de recursos de outros entes para a execução de suas atividades finalísticas, através de instrumentos como os termos de descentralização, convênios e/ou contratos, resultado do exercício da política de 
captação de recursos. Neste contexto estão inseridas as FAs (UFSC, 2015a).

A relação entre as universidades públicas federais e as FAs é vista como salutar, pois os indicadores de excelência de uma universidade baseiam-se fundamentalmente no impacto e relevância da pesquisa produzida, na qualidade de ensino e na formação de recursos humanos competitivos para enfrentar os desafios dos problemas nacionais, de inovação e transferência de conhecimento com abordagens multi, inter e transdisciplinares de forma a responder aos anseios da sociedade e promover o desenvolvimento com sustentabilidade (GIANINI, 2014).

As Fundações tiveram sua origem e desenvolvimento, no Brasil e no mundo, associada a uma intenção de solidariedade e busca da transformação social, pautada no benefício da sociedade em geral (ROCHA, 2012). Sua existência remonta aos primórdios da humanidade, quando os homens que tinham amor pela arte, cultura e sabedoria, destinavam bens às finalidades sociais, transmitindo para a sociedade seus ideais e suas convicções (PAES, 2004).

No Brasil, as FAs aparecem como parte de uma nova esfera pública, sem estar diretamente ligadas ao Estado e tampouco vinculadas a ele, se dedicando a atender necessidades sociais que os governos não conseguem satisfazer. Nesta perspectiva, além de não vislumbrarem lucros, elas possuem características de entidades estatais ao prestarem serviços de natureza iminentemente públicos (ROCHA, 2012).

Para atender as características e finalidades sociais das FAs, os legisladores brasileiros registraram no Código Civil de 2002 (BRASIL, 2002), que elas somente poderão ser criadas para atender a finalidades educacionais, culturais, religiosas e voltadas à preservação do meio e promoção da ética e cidadania, cabendo ao Ministério Público a sua fiscalização.

No que concerne à educação, a promulgação da Lei n 8.958/94 (BRASIL, 1994) formalizou a relação das IFES com as FAs, sendo regulamentada pelo Decreto nº . 7.423/2010 (BRASIL, 2010). Entretanto, mesmo tendo seu credenciamento pelo MEC aprovado com este Decreto, sua natureza jurídica já existe desde a Constituição Federal de 1937 (BRASIL, 1937) e sua atuação nas IFES ocorre desde a década de 60 (VELLOSO; MARQUES, 2005). A natureza jurídica das FAs é de direito privado, sem fins lucrativos, sendo que o registro e credenciamento no MEC e no MCTI passou a ser condição obrigatória para que possam exercer suas atividades (MEC, 2015).

A maioria das FAs foi deflagrada na década de 70 (REIS; CARLSON, 2012) se proliferando a partir dos anos 1990, justificadas na proposta de dar flexibilidade ao rígido sistema burocrático que prevalece nas IES públicas, embutida no Plano Diretor de Reforma do Aparelho do Estado (SGUISSARDI, 2002).

O crescimento da atuação das FAs junto às universidades públicas federais é explicada também por Santos (2005) ao descrever as três grandes crises que assolaram as universidades 
ocidentais, a saber: de hegemonia, de legitimidade e institucional. Esse fenômeno foi vivenciado no Brasil a partir dos anos de 1990, com a eminência das políticas neoliberais que interferiram sobremaneira nas relações entre as universidades e o Estado, levando essas instituições a um caos financeiro (SANTOS, 2005).

Paes (2004) elenca algumas questões que fazem com que as FAs exerçam o papel de flexibilizar e dar agilidade à implantação de seus projetos, como a falta de autonomia das universidades federais. Para ele, esse princípio constitucional, estampado no artigo 207 (BRASIL, 1988), ainda está longe de ser efetivado, pois os recursos necessários aos projetos de ensino, pesquisa e extensão muitas vezes não dão discricionariedade aos gestores. Outro fator é a predominância de estruturas de gestão rígidas e inadequadas, que dificultam o seu andamento regular. Portanto, essas parcerias contribuem para a redução da excessiva carga burocrática que envolve a administração pública (PAES, 2004).

A relação definida pela Lei $n^{\circ}$ 8958/94, entre as FAs e as IFES ocorre por meio da celebração de convênios e contratos por prazo determinado (BRASIL, 1994). E, nesta condição, as universidades atuam em conjunto com as FAs para atender as demandas crescentes da sociedade, considerando que as políticas de financiamento da educação por parte do Estado tornaram-se mais restritivas a partir dos anos 1990 devido à insuficiência de recursos para investimento nessa área (SANTOS, 1999).

Segundo Alves e Azevedo (2007), as FAs abreviam caminhos administrativos, e por isso, podem estimular mudanças na burocracia universitária, internamente, deslocando o poder gerencial no organograma oficial da universidade.

No âmbito da UFSC, a norma que regulamenta as relações com as FAs é a $R N n^{\circ}$ 13/CUn/2011 (UFSC, 2011a). De acordo com essa resolução, a UFSC pode celebrar convênios e contratos com prazos determinados com suas FAs devidamente credenciadas a fim de dar apoio a ações de extensão, projetos de ensino, pesquisa e de desenvolvimento institucional, científico e tecnológico, inclusive na gestão administrativa e financeira estritamente necessária à execução desses projetos e ações, desde que observados os ditames legais e as regras estabelecidas na referida normativa (UFSC, 2011a).

Dada esta relação, observa-se que as FAs atuam no sentido de potencializar o desempenho das atividades finalísticas da universidade. A análise dos seus resultados demonstra a dimensão das ações colaborativas das FAs que atuam no interior da UFSC, em relação aos investimentos em ensino, pesquisa e extensão. 


\section{A UFSC E SUAS FUNDAÇõES DE APOIO}

A seguir serão brevemente caracterizadas a UFSC e as suas FAs para na sequência serem apresentados e analisados os dados de acordo com a proposta da pesquisa.

De acordo com seu relatório de gestão, a UFSC foi criada em 18 de dezembro de 1960 pela Lei $\mathrm{n}^{\circ}$ 3.849/60 (BRASIL, 1960). Possui atualmente 5 campi e 11 Centros de Ensino, por meio dos quais celebra contratos e convênios com quatro Fas - a FUNJAB, a FEESC, a FAPEU e a FEPESE - a fim de receber apoio em projetos de ensino, pesquisa, extensão, desenvolvimento institucional, científico e tecnológico e estímulo à inovação (UFSC, 2015b).

Para efetivamente gerenciar seus projetos junto às suas FAs, a UFSC conta com uma série de regulamentações normativas internas, tais como a $\mathrm{RN} \mathrm{n}^{\circ} 13 / \mathrm{CUn} / 2011$, que dispõe sobre as normas que regem as relações entre a UFSC e as suas FAs; a RN nº 47/CUn/2014 que dispõe sobre a atividade de pesquisa na UFSC; a RN no 03/CUn/2011 que dispõe sobre as normas que regem as ações de extensão, e a RN nº. 15/CUn/2011 (UFSC, 2011b) que dispõe sobre a Pós-Graduação lato sensu na UFSC.

Estas resoluções estabelecem os parâmetros para a regulamentação da abertura, acompanhamento e tramitação de projetos no interior da instituição, e também definem as taxas que deverão ser distribuídas por centro, departamento de origem e demais departamentos envolvidos no projeto, nos setores centrais de apoio e para UFSC destinado ao fundo de desenvolvimento institucional a ser criado e regulamentado em resolução específica, para ser aplicado na melhoria da infraestrutura institucional de acordo com a sua classificação, conforme demonstrado na tabela que segue:

Tabela 1. Demonstrativo de taxas pagas à UFSC de acordo com Resoluções específicas de cada projeto ${ }^{2}$

\section{Interessados}

Áreas

Ensino

Pesquisa

Extensão

\begin{tabular}{lccc}
\hline UFSC & $4 \%$ & $4 \%$ & - \\
Departamento/Centros & $10 \%$ & $3 \%$ & $2 \%$ \\
PROPG/PAAP/FUNEX & $5 \%$ & $3 \%$ & $3 \%$ \\
\hline
\end{tabular}

Fonte: Adaptação da RN no 47/CUn/2014, RN n ${ }^{\circ}$ 03/CUn/2009 e RN n 15/CUn/2011.

\footnotetext{
${ }^{2}$ PROPG/PAAP/FUNEX: Pró-Reitoria de Pós-Graduação / Programa de Apoio às Atividades de Pesquisa / Fundo de Apoio a Projetos de Extensão
} 
As atividades de pesquisa são as ações e projetos desenvolvidos para geração e ampliação do conhecimento e de sua eventual aplicação para o bem da comunidade, tendo como objetivo imprescindível à produção intelectual. A extensão universitária é um processo educativo, cultural e científico, articulado ao ensino e à pesquisa de forma indissociável, que viabiliza a relação transformadora entre a universidade e a sociedade e o ensino tem por objetivo proporcionar formação de nível superior, de natureza acadêmica ou profissional, que habilite à obtenção de grau universitário.

Cabe destacar que projetos financiados com recursos de natureza pública pagam a taxa no percentual de $1 \%$ para UFSC, independente do tipo de projeto.

\section{Análise dos projetos gerenciados pelas Fundações de Apoio na UFSC}

O estudo compreendeu a análise dos contratos e convênios firmados entre a UFSC e as FAs que atuam junto à instituição de acordo com os dados disponibilizados no site eletrônico destas entidades. Em todos os sites buscou-se pela opção Projetos, sendo que a FUNJAB e a FEPESE apresentam esta opção na sua página inicial. Ao ser selecionada a opção, o internauta é direcionado diretamente para a relação de projetos em andamento ou concluídos. A FUNJAB relaciona os projetos por número de contrato e título. A FEPESE relaciona os projetos por um número e nome do projeto. Na FAPEU o acesso é feito através do menu transparência, na opção Projetos em execução, que apresenta a relação dos projetos em execução e executados, com número, título, data de início e término, órgão, departamento, número do contrato, número de cadastro no Sistema de Gestão Administrativa - SPA da UFSC e tipo. Na FEESC o acesso é realizado através do menu Gestão de Projeto na opção Projeto em execução que relaciona os projetos por data e nome, podendo a busca ser refinada por ano. Nesta pesquisa, realizada no ano de 2016, foram utilizados os dados referentes ao ano de 2015 com vistas a conhecer as áreas de maior destaque em quantitativo e volume financeiro de projetos deste período, bem como avaliar a disponibilidade dessas informações nos sites das FAs participantes do estudo.

O volume de recursos financeiros gerenciados pelas FAs no interior da UFSC durante o ano de 2015 é demonstrado na figura 1, em percentuais: 


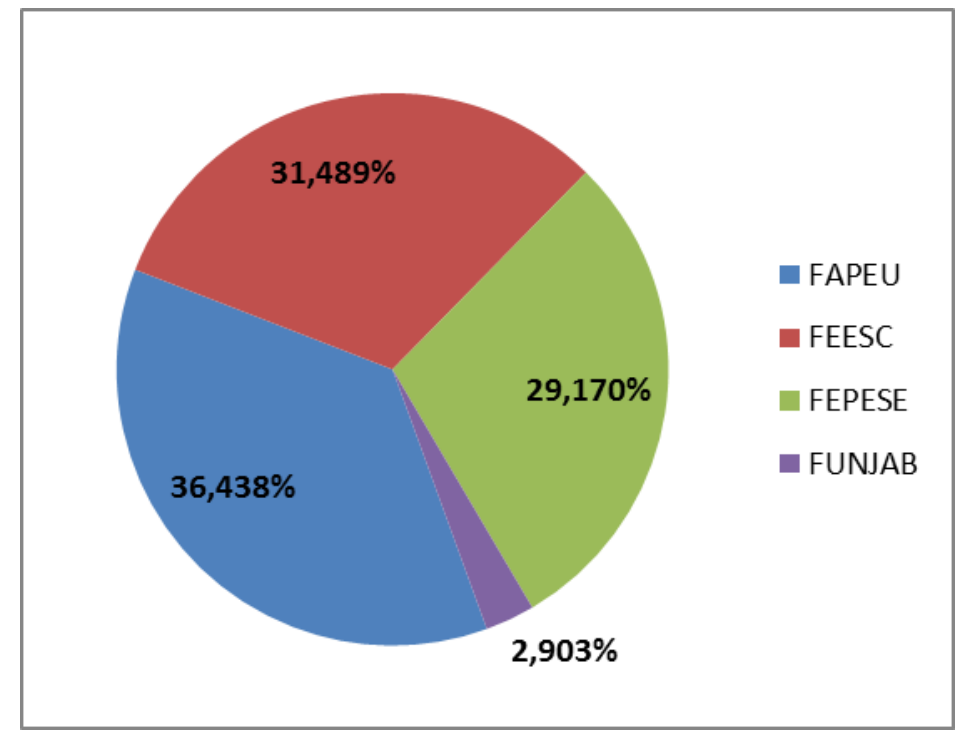

Figura 1. Porcentagem dos recursos financeiros por fundação de apoio, firmados em 2015. Fonte: Elaborado pelos autores

A análise dos contratos firmados pelas FAs no ano de 2015 apresenta um volume de recursos no total de $\mathrm{R} \$ 109.782 .793,34$. Constata-se que deste total, 36,4\% correspondem apenas aos projetos conveniados com a FAPEU. A FEESC e FEPESE registraram os percentuais de $31,49 \%$ e $29,17 \%$ respectivamente e a FUNJAB movimentou 2,90\% do montante de recursos conveniados no ano de 2015. Ressalta-se que o montante, $\mathrm{R} \$ 2.928 .859,17$ estão vinculados à projetos conveniados entre as FAs e a Universidade Federal da Fronteira Sul (UFFS). Salienta-se ainda que dos 77 projetos analisados, 7 destes, todos conveniados entre a UFSC e a FAPEU, encontravam-se com os valores indisponíveis, protegidos por cláusula contratual de sigilo e confidencialidade, apesar das demais fundações registrarem projetos na mesma situação, porém, tornando públicos os valores pactuados.

Os dados referentes aos recursos financeiros movimentados na UFSC nas áreas de ensino, pesquisa e extensão, são apresentados na tabela 2, que demonstra a distribuição dos valores destinados por área, o percentual correspondente e o quantitativo de projetos:

Tabela 2. Distribuição dos recursos conveniados com as fundações em 2015 por área de atuação da UFSC

\begin{tabular}{lrrcc}
\hline $\begin{array}{l}\text { Área de } \\
\text { atuação }\end{array}$ & Valores & $\begin{array}{c}\text { Distribuição dos } \\
\text { valores }\end{array}$ & Quant. de projetos \\
\hline Ensino & $\mathrm{R} \$$ & $4.453 .295,17$ & $4,17 \%$ & 4 \\
\hline Extensão & $\mathrm{R} \$$ & $51.767 .813,28$ & $48,45 \%$ & 31 \\
\hline Pesquisa & $\mathrm{R} \$$ & $49.753 .750,16$ & $46,56 \%$ & 33 \\
\hline Institucional & $\mathrm{R} \$$ & $879.075,56$ & $0,82 \%$ & 3
\end{tabular}




\section{Total Geral \\ R\$ 106.853.934,17 \\ $100,00 \%$ \\ 71}

Fonte: Elaborado pelos autores

Ao analisar os recursos conveniados com as FAs no ano de 2015 de acordo as áreas de atuação da UFSC, depreende-se que há uma distribuição equânime entre os recursos distribuídos entre a pesquisa e a extensão, as quais possuem respectivamente $46.56 \%$ e $48,45 \%$ dos valores conveniados com as FAs. A área de ensino registrou valores da ordem de $4,17 \%$ do montante de recursos. Ressalta-se que 3 destes projetos foram caracterizados pelos agentes envolvidos como "institucionais" por objetivarem ações voltadas aos campus da UFSC ( 2 projetos), ou por estarem associados a projetos institucionais da UFSC (1 projeto), financiadas através de descentralização de recursos.

As áreas de pesquisa e extensão movimentaram valores muito próximos tanto no montante de recursos como no quantitativo de projetos. Destaca-se que a mediana ${ }^{3}$ dos projetos de extensão firmados em 2015 registrou o valor de $\mathrm{R} \$ 587.727,27$. Isso significa que 50\% dos projetos firmados entre as FAs e a UFSC apresentavam valores superiores ao valor da mediana. Essa medida não pode ser atribuída à área de pesquisa, haja vista que dos projetos conveniados no ano de 2015, 7 destes, firmados com a FAPEU, estão resguardados por uma condição de sigilo, não apresentando seus respectivos valores.

Considerando a estrutura atual da UFSC, com 11 Centros de Ensino ${ }^{4}$ e 5 campi $^{5}$, torna-se necessário apresentar quais Centros de Ensino possuem a participação mais efetiva no desenvolvimento de projetos, bem como a abrangência financeira.

No que se refere à quantidade de projetos por Centro de Ensino, nota-se uma concentração em projetos vinculados ao CTC (35 projetos, correspondendo a 52,24\% do total). Ressalta-se o fato do CTC e o CCS serem responsáveis por 70,15\% de todos os projetos conveniados com as FAs na UFSC (ambos totalizam um quantitativo de 47 projetos). Ainda, não existem registros de projetos conveniados no ano de 2015 em outros 3 Centros de Ensino, o CCB, o CCJ e o CFM, conforme evidenciado na figura 2:

\footnotetext{
${ }^{3}$ Corresponde ao valor que divide uma distribuição ao meio, deixando 50\% dos menores valores de um lado e os $50 \%$ dos maiores valores de outro (BARBETA, 2010).

${ }^{4}$ Os 11 Centros da UFSC são: Centro Socioeconômico (CSE), Tecnológico (CTC), de Ciências Agrárias (CCA), de Ciências Biológicas (CCB), de Comunicação e Expressão (CCE), de Ciências da Educação (CED), de Ciências Físicas e Matemáticas (CFM), de Ciências Jurídicas (CCJ), de Ciências da Saúde (CCS), de Filosofia e Ciências Humanas (CFH) e de Desportos (CDS).

${ }^{5}$ Os 4 Campi da UFSC são: Araranguá, Curitibanos, Joinville e Blumenau.

\begin{tabular}{l|l|l|l|l|} 
Rev. Inter. Educ. Sup. & Campinas, SP & v.3 & n.2 & p.270-290
\end{tabular}
maio/ago. 2017
} 


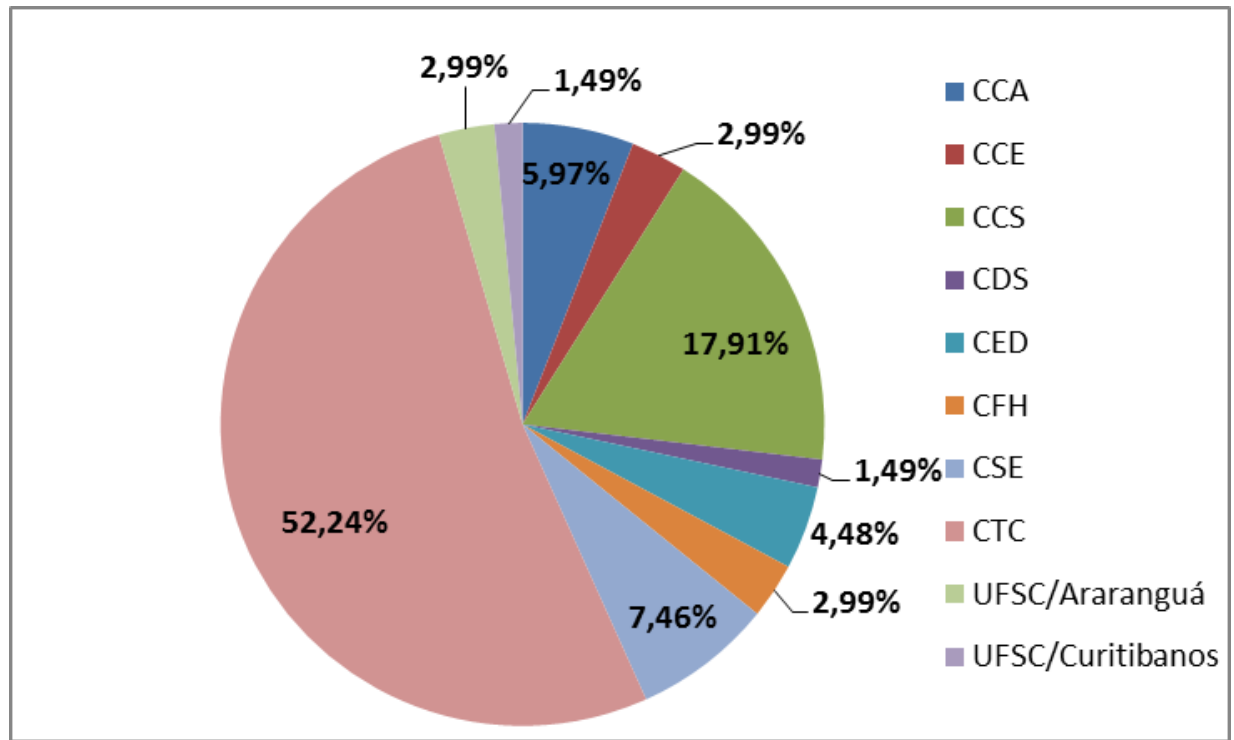

Figura 2. Distribuição do quantitativo de projetos conveniados com as fundações de apoio pela UFSC e sua distribuição por Centro de ensino em $2015^{6}$.

Fonte: Elaborado pelos autores

Ao analisar a distribuição de recursos por Centros de Ensino da UFSC, constata-se uma grande concentração dos recursos financeiros em projetos vinculados ao CTC, onde estão alocados $56,44 \%$ (correspondendo a $\mathrm{R} \$ 58.818 .920,73$ ) dos recursos financeiros dos projetos conveniados com as FAs da UFSC no ano de 2015.

A figura 3 ilustra o percentual de recursos financeiros conveniados com as FAs por Centro de Ensino da UFSC:

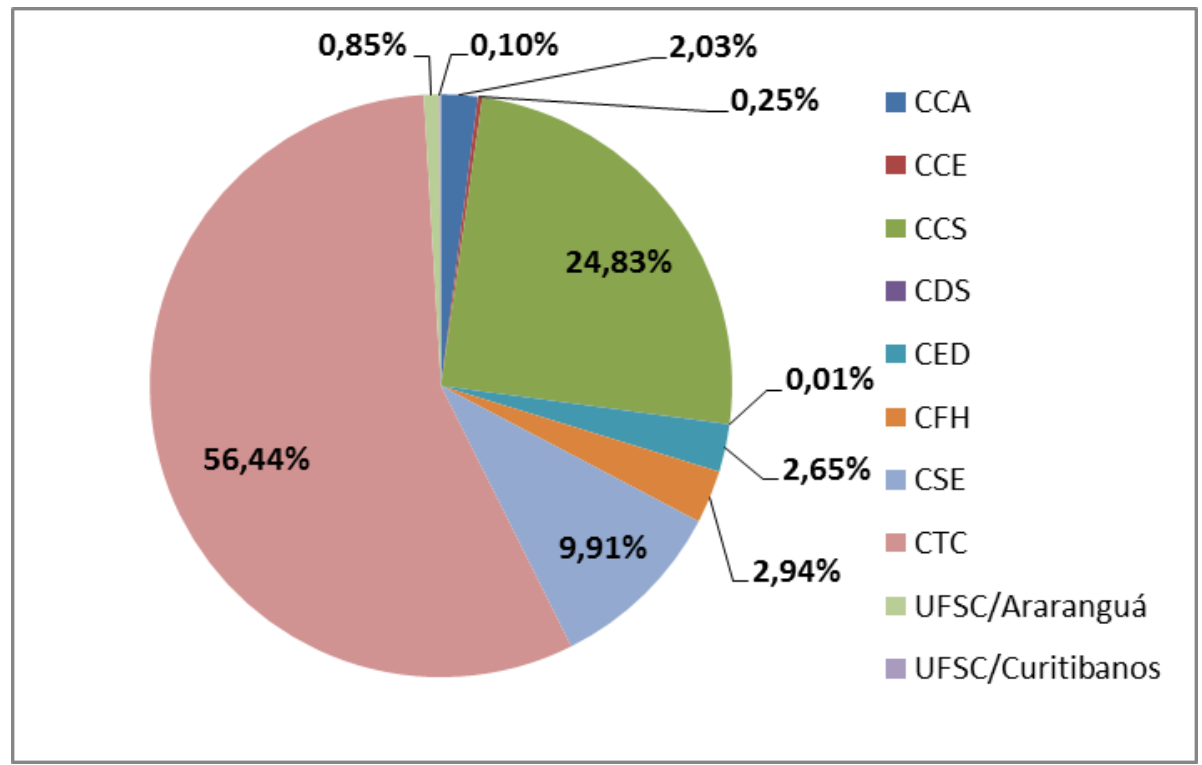

${ }^{6}$ Quatro projetos de extensão não foram considerados na figura 2 por estarem as sociados a órgãos da administração central da UFSC. 
Figura 3. Porcentagem dos recursos financeiros conveniados com as fundações por Centro de Ensino da UFSC em $2015^{7}$

Fonte: Elaborado pelos autores

A seguir é demonstrada a distribuição dos projetos de ensino, pesquisa e extensão por Centro de Ensino.

Com relação aos projetos de ensino foram registrados apenas quatro projetos - vinculados respectivamente ao CCA, ao CTC, ao campus Araranguá e a Comissão Permanente de Vestibular (COPERVE) que responde à administração central. Os dados registrados acerca desses projetos representam um montante de $\mathrm{R} \$ 2.459,127,20$ e são demonstrados na tabela a seguir. O projeto de ensino associado a COPERVE não consta na tabela 3, pois os dados a ele correspondentes não foram acessados.

Tabela 3. Distribuição dos projetos de ensino por Centro de Ensino da UFSC em 2015

\begin{tabular}{lccc}
\hline \multicolumn{1}{c}{ Centro de Ensino } & Quant. & \% da quantidade & Total R\$ \\
\hline Ensino & $\mathbf{3}$ & $\mathbf{1 0 0 , 0 0 \%}$ & $\mathbf{R} \$ \mathbf{2 . 4 5 9 . 1 2 7 , 2 0}$ \\
\hline CCS & 1 & $33,33 \%$ & $\mathrm{R} \$ 1.893 .067,20$ \\
\hline CTC & 1 & $33,33 \%$ & $\mathrm{R} \$ 359.960,00$ \\
\hline UFSC/Araranguá & 1 & $33,33 \%$ & $\mathrm{R} \$ 206.100,00$ \\
Total Geral & $\mathbf{3}$ & $\mathbf{1 0 0 , 0 0 \%}$ & $\mathbf{R} \$ \mathbf{2 . 4 5 9 . 1 2 7 , 2 0}$ \\
\hline
\end{tabular}

Fonte: Elaborado pelos autores

A distribuição dos projetos de pesquisa por Centro de Ensino é apresentada na tabela 4, evidenciando os Centros que apresentam maior proporção de projetos de pesquisa na instituição:

Tabela 4. Distribuição dos projetos de pesquisa por Centro de Ensino da UFSC em 2015.

\begin{tabular}{lcccc}
\hline \multicolumn{1}{c}{ Centro de Ensino } & Quant. & \% da quantidade & & Total R\$ \\
\hline Pesquisa & $\mathbf{3 3}$ & $\mathbf{1 0 0 , 0 0 \%}$ & R\$ & $\mathbf{4 9 . 7 5 3 . 7 5 0 , 1 6}$ \\
\hline CCA & 2 & $6,06 \%$ & R $\$$ & $2.024 .068,26$ \\
\hline CCS & 3 & $9,09 \%$ & R $\$$ & $10.205 .277,41$
\end{tabular}

\footnotetext{
quatro projetos de extensão não foram considerados na figura 3 por estarem associados a órgãos da administração central da UFSC.
}

7 


\begin{tabular}{lccrr} 
CTC & 27 & $81,82 \%$ & $\mathrm{R} \$$ & $36.844 .416,49$ \\
\hline UFSC/Araranguá & 1 & $3,03 \%$ & $\mathrm{R} \$$ & $679.988,00$ \\
\hline Total Geral & $\mathbf{3 3}$ & $\mathbf{1 0 0 , 0 0 \%}$ & $\mathbf{R} \$$ & $\mathbf{4 9 . 7 5 3 . 7 5 0 , 1 6}$
\end{tabular}

Fonte: Elaborado pelos autores

Verifica-se que os projetos de pesquisa estão concentrados em 3 Centros de Ensino da UFSC no campus trindade e no campus de Araranguá. Dos 33 projetos de pesquisa, 27 estão vinculados ao CTC (correspondendo a $81,82 \%$ dos projetos de pesquisa registrados nas FAs em 2015). Ressalta-se que o CTC movimentou 74,05\% dos recursos financeiros destinados a área de pesquisa. A proporção de projetos de extensão por Centro de ensino é demonstrada na tabela 5:

Tabela 5. Distribuição dos projetos de extensão por Centro de Ensino da UFSC em $2015^{8}$

\begin{tabular}{lcccr}
\hline Centro de Ensino & Quant. & \% da quantidade & & \multicolumn{1}{c}{ Total R\$ } \\
\hline Extensão & $\mathbf{2 8}$ & $\mathbf{1 0 0 , 0 0 \%}$ & $\mathbf{R} \$$ & $\mathbf{5 1 . 1 2 5 . 1 8 8 , 0 5}$ \\
\hline CCA & 1 & $3,57 \%$ & $\mathrm{R} \$$ & $45.069,00$ \\
CCE & 2 & $7,14 \%$ & $\mathrm{R} \$$ & $257.446,00$ \\
CCS & 8 & $28,57 \%$ & $\mathrm{R} \$$ & $13.780 .026,84$ \\
\hline CDS & 1 & $3,57 \%$ & $\mathrm{R} \$$ & $14.995,00$ \\
CED & 3 & $10,71 \%$ & $\mathrm{R} \$$ & $2.757 .865,70$ \\
\hline CFH & 2 & $7,14 \%$ & $\mathrm{R} \$$ & $3.064 .852,27$ \\
\hline CSE & 4 & $14,29 \%$ & $\mathrm{R} \$$ & $10.089 .244,00$ \\
\hline CTC & 6 & $21,43 \%$ & $\mathrm{R} \$$ & $21.014 .624,24$ \\
\hline UFSC/Curitibanos & 1 & $3,57 \%$ & $\mathrm{R} \$$ & $101.065,00$ \\
\hline Total Geral & $\mathbf{2 8}$ & $\mathbf{1 0 0 , 0 0 \%}$ & $\mathbf{R} \$$ & $\mathbf{5 1 . 1 2 5 . 1 8 8 , 0 5}$ \\
\hline
\end{tabular}

Fonte: Elaborado pelos autores

No que tange aos projetos de extensão, o CCS possui aproximadamente $1 / 3$ dos projetos de extensão conveniados com as FAs no ano de 2015, seguido pelo CTC e o CSE, com respectivamente 6 e 4 projetos. Ressalta-se que os 3 Centros de Ensino mencionados

\footnotetext{
${ }^{8}$ Três projetos de extensão não foram considerados na tabela 3 por estarem associados a órgãos da administração central da UFSC.
} 
respondem por 64,29\% dos projetos vinculados à área de extensão. Cabe frizar que, embora com menor quantidade de projetos de extensão, o CTC se destaca no volume de recursos, que correspondem à $41,10 \%$ do total. No tocante aos projetos de ensino, foram registrados apenas quatro projetos (vinculados respectivamente ao CCA, ao CTC, ao campus Araranguá e à órgão da administração central) que movimentaram o montante de $R \$ 2.459,127,20$ e 3 projetos categorizados como institucional (vinculados ao CCA, ao CSE e ao CTC) movimentando recursos na ordem de $\mathrm{R} \$ 879.075,56$.

A análise dos projetos de acordo com a distribuição por Centro de Ensino evidenciou que o CTC e o CCS são os Centros de Ensino que mais desenvolvem projetos, sendo que o CTC apresenta 27 projetos de pesquisa e 6 projetos de extensão, e 1 de ensino, totalizando 34 projetos. O CTC possui 10 cursos de graduação e 13 programas de pós-graduação stricto sensu, a maioria deles voltados aos campos da tecnologia e inovação. Portanto, seus projetos são de cunho mercadológico, pois fomentam pesquisas voltadas à produção de conhecimentos, criar soluções para o setor produtivo e promover o crescimento econômico, em âmbito nacional.

O CCS, por sua vez, movimentou 3 projetos de pesquisa e 8 de extensão e 1 de ensino, totalizando 12 projetos, sendo a segunda área mais atuante na instituição, cujos os fins são de cunho social, com a maioria de seu financiamento público e desenvolvimento voltados à área da saúde. Nesse âmbito, a maioria possui caráter de prestação de serviços especializados gratuitamente à população, colaborando para a aplicabilidade do conhecimento gerado na UFSC, na forma de soluções para a sociedade.

O CSE é o terceiro Centro de Ensino mais atuante, com 4 projetos de extensão, voltados tanto para a área social quanto mercadológica, atuando nos dois eixos. Os outros Centros e campi analisados mantiveram uma proporção que varia de 1 a 3 projetos, sendo que dos 11 Centros de Ensino e dos 4 campi, 5 não tiveram nenhum escopo neste período, sendo o CCJ, CCB, CFM e o campus de Joinville e Blumenau.

Esses dados sugerem que a UFSC tem se destacado, na pesquisa, no campo da tecnologia, seguida pela saúde; e na extensão, no campo da saúde, seguido pela tecnologia e pelas ciências sociais aplicadas, mantendo um equilíbrio em setores como comunicação, educação e ciências sociais que desenvolveram até 3 projetos, seguidos pela agricultura e desportos com 1 projeto. Na extensão, embora a quantidade de projetos do CCS sejam maiores, o CTC se destaca pelo total de recursos movimentados, fator significativo para a análise das áreas do conhecimento que congregam maiores investimentos financeiros.

Considerando o número de projetos e o respectivo montante de recursos por área de atuação, 3 projetos não foram considerados nesta análise, por estarem classificados como institucionais. Constata-se que a FAPEU responsabilizou-se pela execução financeira e administrativa de 18 projetos de extensão, de um total de 31 , movimentando o valor de $\mathrm{R} \$$ 
20.950.844,71 com recursos destinados para a área de extensão. A atuação da FEESC esteve fortemente associada à área de pesquisa, gerenciando 21 projetos (de um total de 24 conveniados em 2015) o que correspondeu ao montante de $\mathrm{R} \$ 26.211 .969,49$. A atuação da FEPESE e FUNJAB voltou-se para o gerenciamento de projetos de extensão haja vista que a FEPESE registrou 11 projetos, dos quais 9 são associados à área de extensão. Já a FUNJAB registrou 4 , sendo 2 de extensão, movimentando valores da ordem de $\mathrm{R} \$ 2.544 .852,27$, como pode ser visualizado na tabela 6 :

Tabela 6. Distribuição dos recursos por fundação e alocação por área de atuação da UFSC e quantitativo de projetos em 2015

\begin{tabular}{cccc}
\hline \multicolumn{1}{c}{ Fundação } & \multicolumn{1}{l}{ Total R\$ } & Quant. de projetos \\
\hline FAPEU & R\$ & $\mathbf{3 7 . 0 7 3 . 5 2 5 , 5 5}$ & $\mathbf{3 1}$ \\
\hline Ensino & $\mathrm{R} \$$ & $4.093 .335,17$ & 3 \\
Extensão & $\mathrm{R} \$$ & $20.950 .844,71$ & 18 \\
\hline Pesquisa & $\mathrm{R} \$$ & $12.029 .345,67$ & 10 \\
\hline FEESC & $\mathbf{R} \$$ & $\mathbf{3 4 . 5 6 9 . 9 4 9 , 4 9}$ & $\mathbf{2 4}$ \\
\hline Ensino & $\mathrm{R} \$$ & $359.960,00$ & 1 \\
\hline Extensão & $\mathrm{R} \$$ & $7.998 .020,00$ & 2 \\
Pesquisa & $\mathrm{R} \$$ & $26.211 .969,49$ & 21 \\
\hline FEPESE & $\mathbf{R} \$$ & $\mathbf{3 1 . 7 8 6 . 5 3 1 , 3 0}$ & $\mathbf{1 1}$ \\
\hline Extensão & $\mathrm{R} \$$ & $20.274 .096,30$ & 9 \\
\hline Pesquisa & $\mathrm{R} \$$ & $11.512 .435,00$ & 2 \\
\hline FUNJAB & $\mathbf{R} \$$ & $\mathbf{2 . 5 4 4 . 8 5 2 , 2 7}$ & $\mathbf{2}$ \\
\hline Extensão & $\mathrm{R} \$$ & $2.544 .852,27$ & 2 \\
\hline Total Geral & $\mathbf{R} \$$ & $\mathbf{1 0 5 . 9 7 4 . 8 5 8 , 6 1}$ & $\mathbf{6 8}$ \\
\hline & & & 2 \\
\hline
\end{tabular}

Fonte: Elaborado pelos autores

A análise dos dados demonstra que a FAPEU, a FEESC e a FEPESE movimentaram um montante de recursos bastante similares ao passo que a FUNJAB registrou movimentação inferior às outras três FAs no período analisado. Verificou-se uma forte concentração de recursos financeiros em projetos vinculados ao CTC e que dois Centros de Ensino da UFSC (CTC e CCS) respondem por 70,15\% do quantitativo de projetos conveniados com as FAS em 2015. Em relação às áreas de atuação, há uma distribuição equânime no quantitativo de 
projetos nas áreas de pesquisa e extensão, porém, a área de ensino registrou números pouco expressivos, visto que projetos de ensino administrados pelas FAs correspondem somente à pós-graduação lato-sensu, registrando apenas quatro projetos vinculados ao: CCA; CTC; campus UFSC/Araranguá e órgão da administração central.

Os demais cursos que recebem fomento para sua execução, como os cursos de graduação à distância, são associados à área de extensão.

Por fim, o comparativo dos dados levantados junto as FAs da UFSC demonstraram a constante participação das FAs para fomentar o tripé ensino, pesquisa e extensão na universidade, visto que análise realizada, limitou-se a apenas 12 meses.

\section{CONCLUSÃ̃o}

A proposta deste artigo foi apresentar um panorama dos projetos de ensino, pesquisa e extensão conveniados com as FAs da UFSC no ano de 2015. O levantamento do volume de projetos firmados neste período baseou-se nos dados disponibilizados no sitio eletrônico de cada uma das FAs, onde alguns projetos, caracterizados como sigilosos, não permitiram o acesso ao valor dos recursos movimentados.

As informações obtidas constituem uma referência para a demonstração de quais são os setores mais ativos nas áreas de ensino, pesquisa e extensão e para examinar a atuação das FAs no interior da UFSC e nas áreas em que ela se destaca. Isso permitiu estabelecer o perfil adotado pela instituição no período, auxiliando os gestores na elaboração e direcionamento de políticas focadas na produção de novos conhecimentos e a prestação de serviços públicos de qualidade, em áreas específicas, de interesse institucional.

Ao apresentar a distribuição de recursos por cada um dos 11 Centros de Ensino e os 5 campi da UFSC, foi possível verificar onde estão concentradas as maiores movimentações de recursos e visualizar quais os setores que gerenciam maior proporção de contratos.

Considerando o volume de recursos evidenciados nas tabelas e gráficos, constata-se que as FAs atuaram significativamente em projetos de pesquisa e extensão, demonstrando uma utilização de recursos praticamente equânime, sendo 48,45\% dos recursos destinados a projetos de extensão ( $\mathrm{R} \$ 57.767 .813,28)$ e $46,56 \%$ dos recursos destinados a projetos de pesquisa ( $\mathrm{R} \$ 49.753 .750,16)$. Este valor é relevante no contexto das universidades públicas federais, onde é comum a pesquisa se destacar como protagonista. Pelos números, percebe-se que na UFSC esta concepção pode ter mudado, seja por influências da própria vocação institucional, por políticas governamentais, ou pelas alterações das próprias normatizações internas.

Como essa é uma constatação preliminar, cabe uma análise mais profunda dessas variáveis 
por meio de investigações direcionadas ao contexto da pesquisa e extensão, podendo ser ampliada com a busca das fontes de financiamento e o valor transferido destes projetos para a instituição, incluindo também as contribuições de cada projeto em âmbito nacional, institucional e para a sociedade. Para a continuidade dessa pesquisa, sugere-se o aprofundamento qualitativo nas áreas em que os projetos são desenvolvidos, podendo ser estratificado por Centro de ensino, por FA, e pela própria área de atuação, como fizeram os autores Melo e Silva (2010) ao abordar os projetos de extensão sob a ótica do compromisso social.

O panorama global de recursos distribuídos por FA, por área de atuação e seus respectivos valores, demonstra a atuação individual de cada FA, no que se refere ao quantitativo de recursos administrados e de projetos identificados por nicho de atuação. Nesse aspecto, verifica-se que a FAPEU, a FEPESE e a FUNJAB se consagram na movimentação de projetos de extensão, enquanto na FEESC predominam os projetos de pesquisa. Apesar da divulgação dos dados referente aos projetos no sítio eletrônico dessas instituições, percebe-se que seus mecanismos de transparência ainda são frágeis, visto que os dados são disponibilizados de maneira distinta e com algumas classificações sem identificação, o que dificulta o acesso à informação.

A demonstração do volume dessas parcerias configura-se como um mecanismo de prestação de contas dos projetos para a comunidade acadêmica da UFSC e para a sociedade interessada. Esse trabalho também cumpre essa prerrogativa, além de ressaltar a importância da publicização dos dados referentes aos projetos gerenciados pelas FAs que atuam como parceiras para a potencialização dos investimentos em ensino, pesquisa e extensão na UFSC e nas IFES em geral.

Os dados analisados evidenciaram que as FAs da UFSC gerenciam e administram um volume de recursos significativo, denotando que se apresentam como meios necessários para gerenciar recursos extraorçamentários no desenvolvimento de projetos de ensino, pesquisa e extensão. A UFSC pode utilizar os dados relacionados ao volume de projetos e de recursos financeiros como fonte de informação para o desenvolvimento de políticas internas e também para futuras projeções no seu PDI, para a realização de novos projetos e atividades, que podem ser de natureza infraestrutural, material e laboratorial, e que levem à melhoria mensurável das condições da universidade, para o cumprimento eficiente e eficaz de sua missão, de acordo com a Lei ${ }^{\circ}$. 8.958/94 e suas resoluções internas.

As informações também subsidiam na visualização de quais áreas mais se desenvolvem no interior da instituição e as que apresentam maior procura de agentes externos, possibilitando que se possa a partir destas informações, criar medidas e incentivos que possibilitem que os demais setores internos da instituição busquem alternativas para sua expansão e desenvolvimento, visto que os Centros de Ensino que não desenvolvem ou desenvolvem poucos projetos obtém menos recursos para investir em seu crescimento. Enfim, essa análise 
é um referencial de informação que pode ser utilizado para diversos encaminhamentos pelos gestores na instituição, no âmbito de planejamento estratégico, político e social.

\section{REFERÊNCIAS}

ALVES, Antônio Marcos dos Santos; AZEVEDO, Mário Luiz Neves de. Fundação de apoio à universidade: uma discussão sobre o conflito entre o público e o terceiro setor. Atos de Pesquisa em Educação, Blumenau, v. 2, n. 3, p.486-507, 09/2007. Disponível em: <gorila. furb.br/ojs/index.php/atosdepesquisa/article/download/758/634>. Acesso em: 10 jul. 2016. BARBETTA, Pedro Alberto. Estatística aplicada às ciências sociais. 7. ed. rev.

Florianópolis: Ed. da UFSC, 2010.

BRASIL. Constituição dos Estados Unidos do Brasil de 10 de novembro de 1937.

Disponível em: <http://www.planalto.gov.br/ccivil_03/constituicao/constituicao.htm> Acesso em: 10 jul. 2016.

BRASIL. Constituição da República Federativa do Brasil de 1988. Brasília, DF, Senado, 1988. Disponível em: 〈http://www.planalto.gov.br/ccivil_03/Constituicao/Constituicao.htm>. Acesso em: 10 jul. 2016.

BRASIL. Decreto no 5.773, de 9 maio de 2006. Dispõe sobre o exercício das funções de regulação, supervisão e avaliação de instituições de educação superior e cursos superiores de graduação e sequenciais no sistema federal de ensino. Disponível em:

<http://www.planalto.gov.br/ccivil_03/_Ato2004-2006/2006/Decreto/D5773.htm\#art79>. Acesso em: 09 jul. 2016.

BRASIL. Decreto 7.423 de 31 de dezembro de 2010. Regulamenta a Lei no 8.958, de 20 de dezembro de 1994, que dispõe sobre as relações entre as instituições federais de ensino superior e de pesquisa científica e tecnológica e as Fundações de Apoio, e revoga o Decreto no 5.205, de 14 de setembro de 2004. Disponível em:

<http://www.planalto.gov.br/ccivil_03/_Ato2007-2010/2010/Decreto/D7423.htm\#art16>.

Acesso em: 16 jun. 2016.

BRASIL. Lei $\mathbf{n}^{\circ} 3.849$ de 18 de dezembro de 1960. Federaliza a Universidade do Rio Grande do Norte, cria a Universidade de Santa Catarina e dá outras providências. Disponível em: 〈http://www.planalto.gov.br/ccivil_03/leis/1950-1969/L3849.htm> Acesso em: 30 set. 2016.

BRASIL. Lei n. 8.958, de 20 de dezembro de 1994. Dispõe sobre as relações entre as Instituições Federais de Ensino Superior e de pesquisa científica e tecnológica e as Fundações de Apoio e dá outras providências. Disponível em:

<http://www.planalto.gov.br/ccivil_03/leis/18958.htm>. Acesso em: 10 jul. 2016.

BRASIL. Lei n 9.394, de 20 dez. 1996. Lei de Diretrizes e Bases da Educação Nacional. Diário Oficial da República Federativa do Brasil. Disponível em: <http://www.planalto.gov.br/ccivil_03/leis/L9394.htm>. Acesso em: 09 jul. 2016. 
BRASIL. Lei 10.406, de 10 de janeiro de 2002. Institui o Código Civil. Disponível em: <http://www.planalto.gov.br/ccivil_03/leis/2002/110406.htm>. Acesso em: 10 jul. 2016 CHIARINI, Tulio; VIEIRA, Karina Pereira. Universidades como produtoras de conhecimento para o desenvolvimento econômico: sistema superior de ensino e as políticas de CT\&I. Revista Brasileira de Economia, v. 66, p. 117-132, 2012.

DIAS SOBRINHO, José. Democratização, qualidade e crise da educação superior: faces da exclusão e limites da inclusão. Educação \& Sociedade (Impresso), v. 31, p. 1223-1245, 2010.

FAPEU. Transparência, projetos em execução. Disponível em: <https://fap6.fapeu.org.br/scripts/fapeusite.pl/swfwfap151xx>. Acesso em: 2 jul. 2016. FEESC. Gestão de projeto, projetos em execução. Disponível em: <http://www.feesc.org.br/site/?pg=projetos-em-execucao>. Acesso em: 2 jul. 2016.

FEPESE. Projetos. Disponível em: <http://novosite.fepese.org.br/?page_id=2698.>. Acesso em: 1 jul. 2016.

FUNJAB. Projetos. Disponível em: <http://funjab.ufsc.br/wp/?page_id=2273>. Acesso em: 1 jul. 2016.

GIANINI, Maria José Soares Mendes. A universidade do século XXI. Disponível em: $<$ http://educacao.estadao.com.br/noticias/geral,artigo-a-universidade-do-seculo-21,115048>. Acesso em: 1 jul. 2016.

GIL, Antônio Carlos. Como elaborar projetos de pesquisa. 4. ed. 7 tiragem. São Paulo: Atlas, 2002.

GOLDENBERG, Mirian. A arte de pesquisar: como fazer pesquisa qualitativa em ciências sociais. 8. ed. Rio de Janeiro: Record, 2004.

LAKATOS, Eva Maria; MARCONI, Marina de Andrade. Fundamentos de metodologia científica. 5. ed. São Paulo: Atlas, 2003.

MEC. Ministério da Educação. Disponível em: <http://portal.mec.gov.br/fundacoes-deapoio/apresentacao.>. Acesso em: 10 jul. 2016.

MELO, Pedro Antônio de. SILVA, Flora Moritz da. Universidade e Compromisso Social: a Prática da Universidade Federal de Santa Catarina. X Colóquio Internacional sobre Gestión Universitária em América del Sur. Mar del Plata, 8, 9 e 10 de dezembro de 2010.

MINAYO, Maria Cecília de Souza; SANCHES, Odécio. Quantitativo, qualitativo: oposição e complementariedade? Metodologia de Pesquisa Qualitativa em saúde. Cadernos de saúde pública. Rio de Janeiro, vol. 9, p.239-248, jul/set. 1993. Disponível em: <http://www.scielosp.org/pdf/csp/v9n3/02.pdf>. Acesso em: 25 jun. 2016.

PAES, José Eduardo Sabo. Fundações e Entidades de Interesse Social. 5. ed. Brasília: Brasília Jurídica, 2004. 
REIS, Arley; CARLSON, Victor Emmanuel Carlson; Fepese 35 anos: Algumas histórias, muitos sentimentos. Florianópolis: Lagoa Editora, 2012.

ROCHA, José Cláudio. O papel das Fundações de Apoio no contexto das universidades públicas no Brasil. Âmbito Jurídico, v. 100, p. 01-15, 2012.

SANTOS, Boaventura de Sousa. A universidade do Século XXI: para uma reforma democrática e emancipatória da universidade. São Paulo: Cortez, 2005.

SANTOS, Boaventura de Sousa. Pela mão de Alice: O social e o político na PósModernidade. 7.ed. Porto: 1999.

SEVERINO, Antônio Joaquim. O ensino superior brasileiro: novas configurações e velhos desafios. Educar, Curitiba, n. 31, p. 73-89, 2008.

SGUISSARDI, Valdemar. Fundações privadas na Universidade pública: a quem interessam? Revista da Avaliação da Educação Superior. Campinas, v.7, n.4, p. 73-97, 2002. Disponível em:

$<$ http://periodicos.uniso.br/ojs/index.php?journal=avaliacao\&page=article \&op=view\&path $\%$ 5B\%5D=1201\&path\%5B\%5D=1191>. Acesso em: 10 jul. 2016.

UFSC. Plano de Desenvolvimento Institucional 2015-2019. Florianópolis: UFSC, 2015a. Disponível em:<http://pdi.ufsc.br/pdi-2015-2019/.>. Acesso em: 25 jun. 2016.

UFSC. Relatório de Gestão 2015: Decisão Normativa - TCU no 146 de 30 de setembro de 2015: Portaria-TCU n 321 de 30 de novembro de 2015. Florianópolis: UFSC, $2015 \mathrm{~b}$.

Disponível em: <http://dpgi.seplan.ufsc.br/files/2016/04/Relat\%C3\%B3rio-deGest\%C3\%A3o-2015.pdf;>. Acesso em: 25 jun. 2016.

UFSC. Resolução n⿳0 03/CUn/2009, de 08 de dezembro de 2019, Dispõe sobre as normas que regulamentam as ações de extensão na Universidade Federal De Santa Catarina. Disponível em: <http://www.fapeu.com.br/docs/003CUn2009Extensao.pdf>. Acesso em: 24 ago. 2016.

UFSC. Resolução n⿳ 13/CUn/2011, de 27 de setembro de 2011, Dispõe sobre as normas que regulamentam as relações entre a Universidade Federal de Santa Catarina e as suas Fundações de Apoio. UFSC, 2011a. Disponível em:

<http://dit.ufsc.br/files/2009/12/Resolu\%C3\%A7\%C3\%A3o-Normativa-13.pdf>. Acesso em: 25 jun. 2016.

UFSC. Resolução no 15/CUn/2011, de 13 de dezembro de 2011, Dispõe sobre a pósgraduação lato sensu na Universidade Federal de Santa Catarina. UFSC, 2011b. Disponível em:

<http://propg.ufsc.br/files/2010/07/Resolu\%C3\%A7\%C3\%A3oNormativa15CUn2011_Curso Especializa\%C3\%A7\%C3\%A3o.pdf>. Acesso em: 24 ago. 2016.

UFSC. Resolução no 47/CUn/2014, de 16 de dezembro de 2014, Dispõe sobre a atividade de pesquisa na Universidade Federal de Santa Catarina Disponível em:

\begin{tabular}{l|l|l|l|l|l} 
Rev. Inter. Educ. Sup. & Campinas, SP & v.3 & n.2 & p.270-290 & maio/ago. 2017
\end{tabular}


<http://propesq.ufsc.br/files/2013/08/Resolu\%C3\%A7\%C3\%A3o_Normativa_47-2.pdf> . Acesso em: 24 ago. 2016.

VELLOSO, Jacques; MARQUES, Paulo Marcello E. Recursos Próprios da UNB, o financiamento das IFEs e a reforma da educação superior. Revista Educação e Sociedade. Campinas, v.26, n.91, p. 655-680, 2005. Disponível em: <http://www.scielo.br/pdf/es/v26n91/a18v2691.pdf>. Acesso em: 01 jul. 2016.

VERGARA, Sylvia Constant. Projetos e relatórios de pesquisa em administração. 14. ed. São Paulo: Atlas, 2013.

\section{${ }^{\mathrm{i}}$ Sobre os autores}

\section{Lilian Wrzesinski Simon}

E-mail: lilian.uffs@gmail.com / ORCID: http://orcid.org/0000-0003-0307-4948

Universidade Federal da Fronteira Sul - Brasil

Mestranda em Administração Universitária pela Universidade Federal de Santa Catarina [UFSC].

Carla Cerdote da Silva

E-mail: carlacerdote@gmail.com / ORCID: http://orcid.org/0000-0002-8135-3910

Universidade Federal de Santa Catarina - Brasil

Mestranda em Administração Universitária pela Universidade Federal de Santa Catarina [UFSC].

Antonio Marcos Machado

E-mail: antoniomarcosmachado1@ gmail.com / ORCID: http://orcid.org/0000-0003-1498-7347

Universidade Federal da Fronteira Sul - Brasil

Mestrando em Administração Universitária pela Universidade Federal de Santa Catarina [UFSC].

José Alvicio Ritter Filho

E-mail: jose.ritter05@gmail.com / ORCID: http://orcid.org/0000-0001-9216-5600

Instituto Federal de Santa Catarina - Brasil

Mestrando em Administração Universitária pela Universidade Federal de Santa Catarina [UFSC].

Larissa Espindola Machado Pereira

E-mail: larissaem87@gmail.com / ORCID: http://orcid.org/0000-0002-2493-7642

Universidade Federal de Santa Catarina - Brasil

Mestranda em Administração Universitária pela Universidade Federal de Santa Catarina [UFSC].

Alexandre Moraes Ramos

E-mail: amrrms@ gmail.com / ORCID: http://orcid.org/0000-0002-3070-9075

Universidade Federal de Santa Catarina - Brasil

Doutor em Engenharia de Produção pela Universitária pela Universidade Federal de Santa Catarina [UFSC]. 